\title{
A RARE CASE OF HYPOGASTRIC OMPHALOCOELE WITH SACRAL MENINGOCOELE
}

Anand Mishra ${ }^{1}$, Shamsher Shrestha², Mandavi Singh ${ }^{3}$, Uttam Shrestha ${ }^{4}$

\section{HOW TO CITE THIS ARTICLE:}

Anand Mishra, Shamsher Shrestha, Mandavi Singh, Uttam Shrestha. "A Rare case of hypogastric omphalocoele with sacral meningocoele". Journal of Evolution of Medical and Dental Sciences 2013; Vol2, Issue 35, September 2; Page: 6762-6765.

ABSTRACT: Omphalocele with sacral meningocele was detected in a primipara on sonography at 17 weeks. The pregnancy was medically terminated on doctor's advice. On observation and dissection of the foetus it was observed that it was a case of hypogastric omphalocele with meningocele. Hypogastric omphalocele results due to failure of tail fold migration during development of abdominal wall. It is accompanied with failure of closure of posterior neuropore resulting in sacral meningocele. These two findings occur concurrently in $40 \%$ of cases. This should be kept in mind while diagnosing omphalocele and meningocele as it will facilitate early termination of pregnancy.

KEY WORDS: hypogastric, omphalocele, meningocele, neuropore

INTRODUCTION: Omphalocele is a congenital defect of the abdominal wall resulting in herniation of abdominal viscera from the umbilical ring. The herniated viscera are covered by the peritoneum on the interior and amnion on the exterior. The herniated viscera consist of a part of intestine, liver and other organs. The umbilical vessels are inserted on the amniotic membrane.

The incidence of omphalocele ranges from 1 in 3000 to 10,000 live births in different regions of the world. Its frequency increase with increase in maternal age and seem to occur more in males as compared to females.

Omphalocele may be seen as an isolated defect but associated anomalies may be seen in $80 \%$ of cases. The most common anomalies seen with omphalocele are congenital heart defect (Tetralogy of Fallot and atrial septal defect), cleft palate and non rotation of bowel.

Omphalocele with neural tube defect is seen in trisomy 18 and also in children born to mother with Valproate exposure during pregnancy.

CASE STUDY: A Primipara with advanced maternal age (31) was referred to the hospital. She did not give any history of taking drugs during pregnancy. During routine sonography at 17 weeks, omphalocele with sacral meningocele was detected in the foetus. Confronted with these findings, the lady agreed to medically terminate her pregnancy.

The aborted fetus was obtained from the department of Obstetrics and dissected to see the viscera herniated in the omphalocele bag. On opening the bag we found that liver, spleen, small intestine and major part of large intestine, urinary bladder have herniated into the bag. The bag was itself formed by two layers. The outer layer was formed by amnion and the inner layer was formed by parietal peritoneum. On opening the spina bifida we found that all the three meningeal layers have herniated into the bag but spinal cord was spared.

DISCUSSION: The abdominal wall develops during 2-4 weeks of gestation by infolding of cephalic (head), caudal (tail) and two lateral folds. Around $6^{\text {th }}$ week, due to inadequate space in abdominal 
cavity, the midgut elongates and projects into body stalk. This is known as physiological hernia. At about 10 weeks of gestation, the intestine derived from midgut loop returns back. After their return, they enlarge and fuse to posterior abdominal wall and take their final position. ${ }^{1,2}$

Three basic theories have been described for the development of omphalocele. Firstly, any arrest in 3 folds may result in an abdominal defect. Secondly, some scientists opine that there is persistence of body stalk resulting in omphalocele. According to third theory, there is failure of abdominal viscera to return in the abdominal cavity at the end of $10^{\text {th }}$ week of development after normal physiological herniation. ${ }^{3,4}$

Majority of omphalocele result from lateral fold defect and are located centrally. The epigastric (cephalic) omphalocele results from head fold defect and is associated with upper midline syndrome of Pentalogy of Cantrell (cleft sternum, diaphragmatic hernia, ectopia cordis and congenital heart defect). Hypogastric (caudal) omphalocele are supposed to be a defect of tail fold and are usually associated with anomalies of hindgut, bladder exostrophy, colonic atresia and sacral meningomyelocoele.5, 6,7

Formation of neural tube from neural plate occurs in $3^{\text {rd }}$ week of gestation and is known as neurulation. Until complete fusion of the neural plate, the cranial and caudal ends of neural tube communicate with the amniotic cavity through anterior and posterior neuropores. Closure of cranial neuropore occurs at about 25th day (8-20 somite stage) whereas the posterior neuropore closes at about $28^{\text {th }}$ day (25 somite stage). Failure in closure of posterior neuropore results in sacral meningocoele. ${ }^{1,2}$

Omphalocele have a high risk of associated anomalies of upto 50\%-70\%.Chromosomal anomalies (30\%) and cardiac defects (30\%-50\%) are the most notable ones associated with it. ${ }^{8} \mathrm{~A}$ pattern of multiple anomalies known as Beckwith Wiedemann syndrome is present in up to $10 \%$ cases of omphalocele. It consists of macroglossia, organomegaly, early hypoglycaemia due to pancreatic hyperplasia and increased risk of Wilm's tumor. All these associated anomalies are usually seen with epigastric omphalocoele. ${ }^{9}$ Whereas with hypogastric omphalocele neural tube defect is the most common anomaly associated. ${ }^{3}$

CONCLUSION: In the current case omphalocele with sacral meningocele must have resulted due to arrest of tail fold migration. The occurrence of meningocele with hypogastric omphalocele is quite common (40\%) and most of the mortality and morbidity in omphalocele is usually due to associated lesion. So it must be always be borne in the mind by the ultrasonologist that a concurrent neural tube defect may coexist with omphalocele and so a prompt diagnosis of this may favour a early termination of pregnancy

\section{REFERENCES:}

1. Sadler TW. Langman's Medical Embryology.11 th ed, Williams and Wilkins. 2009;73-76

2. Moore KL, Persaud TVN .The developing human.8 ${ }^{\text {th }}$ ed. Saunders 2009:226-234

3. Ledbetter DJ. Omphalocele and gastroschisis. Surg Clin N Am 2006;86: 249-260

4. Vermeej- Kiers C, Hartwig NG, Vaderweff J F. Embryological development of ventral body wall and it's congenital malformation. Semin Pediatr Surg 1996; 5(2):82-89

5. deVries PA. The pathogenesis of gastroschisis and omphalocele. J Pediatr Surg 1980; 15(3): 245-251 


\section{CASE REPORT}

6. Hwang PJ, Kouseff BJ. Omphalocele and gastroschisis: an 18 year review study. Genet Med 2004;6(4): 232-236

7. Gollop RT. A case of prenatal diagnosis of fetal hydantoin syndrome by ultrasound. Genet Mol Biol 1999; 22(2): 147-150.

8. Nyberg DA, Fitzsimmons j, Mack LA et al. Chromosomal anomalies in foetuses with omphalocele. Significance of omphalocele contents. J Ultrasound Med 1989; 8 (6): 299-308

9. Nicolaides $\mathrm{KH}$, Snijders RJ, Cheng $\mathrm{HH}$, et al. Fetal gastro-intestinal and abdominal wall defects: associated malformations and chromosomal abnormalities. Fetal Diagn Ther 1992; $7(2): 102-15$

Fig. 1: Fetus with omphalocele.

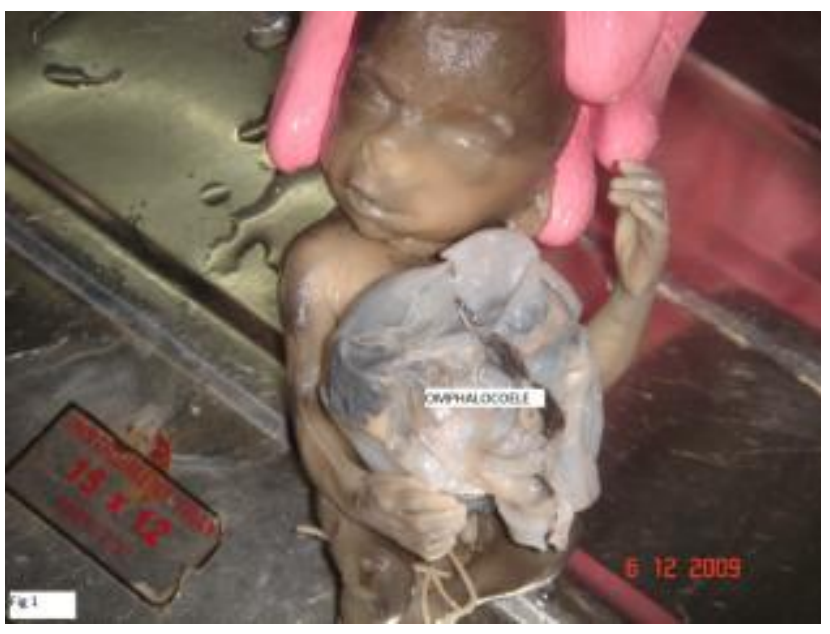

Fig. 2: Fetus with dissected omphalocele bag showing herniated viscera.

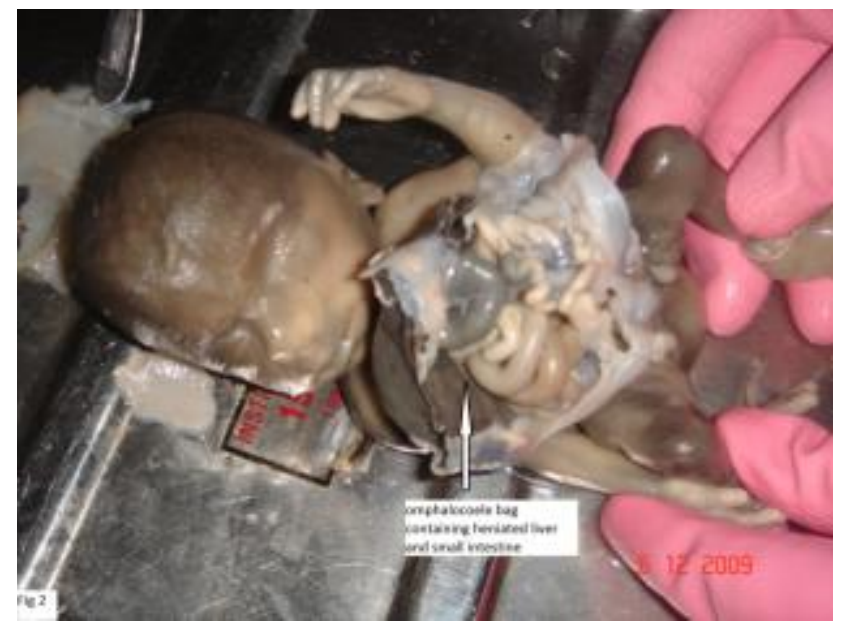




\section{CASE REPORT}

Fig. 3: Fetus with sacral meningocele.

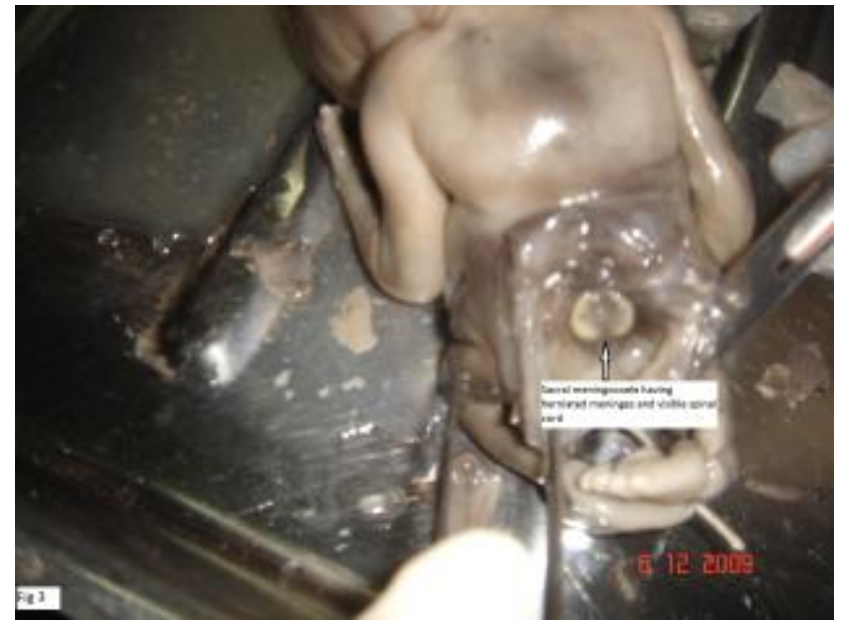

\section{AUTHORS:}

1. Anand Mishra

2. Shamsher Shrestha

3. Mandavi Singh

4. Uttam Shrestha

\section{PARTICULARS OF CONTRIBUTORS}

1. Associate Professor, Department of Anatomy, Institute of Medical Sciences, B.H.U, Varanasi.

2. Assistant Professor, Department of Anatomy, BPKIHS, Dharan, Nepal.

3. Professor, Department of Anatomy, I.M.S, B.H.U, Varanasi.
4. Assistant Professor, Department of Anatomy, Patan Academy of Health Sciences, Patan, Nepal.

\section{NAME ADRRESS EMAIL ID OF THE} CORRESPONDING AUTHOR:

Dr. Anand Mishra,

Associate Professor,

Department of Anatomy,

Institute of Medical Sciences,

B.H.U, Varanasi - 221005.

Email - dranand5@rediffmail.com

Date of Submission: 22/08/2013.

Date of Peer Review: 23/08/2013.

Date of Acceptance: 28/08/2013.

Date of Publishing: 30/08/2013 